\title{
Augmented Lagrange Hopfield Network for Economic Emission Load Dispatch Problem with Quadratic Fuel Cost Function
}

\author{
Cuong Dinh Tran* and Sang Dang Ho \\ Faculty of Electrical and Electronics Engineering, Ton Duc Thang University \\ No. 19 Nguyen Huu Tho Str., Tan Phong W., Dis. 7, HCM City, Vietnam \\ \{trandinhcuong,hodangsang\}@tdt.edu.vn
}

\begin{abstract}
This paper proposes an augmented Lagrange Hopfield Network (ALHN) based method for solving economic emission dispatch (EELD) problem with quadratic fuel function. The ALHN is the combination of augmented Lagrange function and Hopfield neural network in aim to improve performance in terms of convergence speed and getting global optimization. In addition to minimizing electricity generation fuel cost, emission released into the air from thermal plants is also another main objective needs to be minimized. In order to test the performance of the proposed ALHN two systems including a three unit system with one load case and a six unit system with three load cases are employed. The obtained result by the ALHN compared to that from other methods has revealed that the proposed ALHN is a very promising artificial intelligent algorithm for solving economic emission load dispatch problem.
\end{abstract}

Keywords: augmented Lagrange function, Hopfield network, economic emission load dispatch, quadratic fuel cost function, two modifications

\section{Nomenclature}

$\mathrm{a}_{\mathrm{i}}, \mathrm{b}_{\mathrm{i}}, \mathrm{c}_{\mathrm{i}}$ : $\quad$ Cost coefficients of thermal unit $i$

$\mathrm{d}_{\mathrm{i}}, \mathrm{e}_{\mathrm{i}}, \mathrm{f}_{\mathrm{i}}$ : $\quad$ Emission coefficients of thermal unit $i$

$\mathrm{B}_{\mathrm{ij}}, \mathrm{B}_{0 \mathrm{i}}, \mathrm{B}_{00}$ : Transmission loss formula coefficients

$\mathrm{N}$ : $\quad$ Number of online generating units

$\mathrm{P}_{\mathrm{D}}$ : $\quad$ Total load demand of the system (MW)

$\mathrm{P}_{\mathrm{L}}$ : $\quad$ Total network loss of the system (MW)

Pi: $\quad$ Output power of unit $i(\mathrm{MW})$

$\mathrm{P}_{\text {imin }}, \mathrm{P}_{\text {imax }}: \quad$ Lower and upper generation limits of unit $i$ (MW)

$\mathrm{w}_{1}, \mathrm{w}_{2} \quad$ Weights corresponding to the fuel cost and NOx emission objectives.

\section{Introduction}

A power system mainly consists of thermal plants to supply electricity to load. There is the fact that the fuel cost of generating electricity from the thermal plant is so expensive, leading the electricity price that customers uses to be high. Besides, the thermal plants are one of the main resources of releasing emission in to the air, causing hotter temperature and climate change for the earth. Therefore, the main objective of the economic emission dispatch problem is to minimize both electricity generation fuel cost and emission [1].

Over decades, many methods have been applied for solving EELD problem such as Improved Hopfield Neural Network Model (IHNN) [2], Tabu Search (TS) [3], fuzzy logic controlled genetic algorithm (FCGA) [4], the Non-dominated Sorting

${ }^{*}$ Corresponding Author 
Genetic Algorithm - II (NSGA-II) [5], Differential Evolution (DE) [6], biogeography-based optimization (BBO) [7], multi-objective differential evolution (MODE) [8], Hybrid Differential evolution-sequential quadratic programming (DESQP) and Hybrid Particle Swarm optimization-sequential quadratic programming (PSO-SQP)[9], parallel synchronous PSO algorithm (PSPSO) [10], Cuckoo Search Algorithm (CSA) [11]. Among the methods, the application of IHNN on the EELD problem is the most limited because it can not deal with complicated problem with nonconvex fuel cost function of thermal units. Besides, the IHNN faces to the local optimization with high number of iteration for convergence. In [6] and [8], the EELD has been successfully solved by DE algorithm based methods. DE has been considered a strong tool for solving optimization problem in engineering field since it could tackle the disadvantage of IHNN, namely considering nonconvex fuel cost function of thermal units; however, the methods requires a careful section of control parameters. Otherwise, the method can fall within the near optimal solution. The difference between DE in [6] and [8] is that MODE in [8] can determine the best compromise solution which can satisfy both cost and emission minimization requirement without using fuzzy mechanism like DE in [6]. The manner enables MODE to reduce the computing procedure and execution time as well. Two hybrid methods employed in [9], DE-SQP and PSO-SQP, are the combination between two individual methods. The advantage of the methods is that they can take advantage of each individual to enhance the solution approaching the global optimization; however, the methods have to cope with the high number of iterations and longer computational time. BBO has been widely and successfully used for solving the EELD problem and obtained superior results to other methods like NSGA-II and Tabu Search. PSO has become a popular method for over decades in electrical engineering especially power system optimization like load dispatch and optimal power flow. Nevertheless, the method needs more improvement performing on the conventional PSO to achieve higher solution. Compared to other meta-heuristic algorithms, CSA can be considered the most efficient method because it gets $100 \%$ convergence rate with higher performance than PSO, DE, etc.

In this paper, an Augmented Lagrange Hopfield Network is proposed for solving the EELD problem considering power losses in transmission systems and limits on generation of thermal units. The effectiveness of the proposed ALHN has been tested on two systems and the obtained results have been compared to those from other methods reported in the article.

\section{Problem Formulation}

In the EELD problem, the main task is to determine power output of each of the set of available thermal units so that both electricity generation fuel cost and emission released into the air by the thermal plant are minimized while satisfying load balance constraint and limits on generation of each unit. Mathematically, the problem is formulated as follows:

The objective is to minimize cost and emission:

$$
\operatorname{Min} \sum_{i=1}^{N} F_{i}=\sum_{i=1}^{N}\left(w_{1} F_{1 i}\left(P_{i}\right)+w_{2} F_{2 i}\left(P_{i}\right)\right)
$$

where:

$$
\begin{aligned}
& F_{1 i}\left(P_{i}\right)=c_{i} P_{i}^{2}+b_{i} P_{i}+a_{i} \\
& F_{2 i}\left(P_{i}\right)=f_{i} P_{i}^{2}+e_{i} P_{i}+d_{i}
\end{aligned}
$$




\section{Subject to:}

1. Power balance constraints: sum of all thermal units generation is equal to load demand and power losses in transmission line.

$$
\sum_{i=1}^{N} P_{i}-P_{L}-P_{D}=0
$$

where power losses $\mathrm{P}_{\mathrm{L}}$ can be defined as below.

$$
P_{L}=\sum_{i=1}^{N_{1}} \sum_{j=1}^{N_{1}} P_{i} B_{i j} P_{j}+\sum_{i=1}^{N} B_{0 i} P_{i}+B_{00}
$$

2. Generator operating limits: power output of each unit should be within its upper and lower generation.

$$
P_{i \min } \leq P_{i} \leq P_{i \max }
$$

3. Weight constraint: sum of fuel cost and emission weight factors equal one

$$
w_{1}+w_{2}=1
$$

where

$$
0 \leq w_{1}, w_{2} \leq 1
$$

\section{ALHN for EELD Problem}

The augmented Lagrange function $L$ of the problem is formulated as follows:

$$
L=\left\{\begin{array}{l}
\sum_{i=1}^{N} w_{1} F_{1 i, m e}\left(P_{i}\right)+w_{2} F_{2 i, m e}\left(P_{i}\right)+\lambda\left(P_{D}+P_{L}-\sum_{i=1}^{N} P_{i}\right) \\
+\frac{1}{2} \sum_{k=1}^{M} \beta\left(P_{L}+P_{D}-\sum_{i=1}^{N} P_{i}\right)^{2}
\end{array}\right\}
$$

where $\lambda$ and $\beta$ are Lagrangian multiplier associated with power balance and penalty factor associated with power balance constraint, respectively.

The energy function $E$ of the problem described in terms of neurons is determined as:

$$
\begin{aligned}
& E=\sum_{i=1}^{N}\left[w_{1} F_{1 i, m e}\left(V_{i}\right)+w_{2} F_{2 i, m e}\left(V_{i}\right)\right]+\lambda\left(P_{D}+P_{L}-\sum_{i=1}^{N} V_{i}\right) \\
& +\frac{1}{2} \beta\left(P_{D}+P_{L}-\sum_{i=1}^{N} V_{i}\right)^{2}+\sum_{i=1}^{N} \int_{0}^{V_{i}} g^{-1}(V) d V
\end{aligned}
$$

The energy function $E$ of the problem is rewritten as follows:

$$
E=\sum_{i=1}^{N}\left(c_{i} V_{i}^{2}+b_{i} V_{i}+a_{i}\right)+\lambda\left(P_{D}+P_{L}-\sum_{i=1}^{N} V_{i}\right)+\sum_{i=1}^{N} \int_{0}^{V_{i}} g^{-1}(V) d V
$$

Where:

$$
\begin{aligned}
& a_{i}=w_{1} a_{i}+w_{2} d_{i} \\
& b_{i}=w_{1} b_{i}+w_{2} e_{i} \\
& c_{i}=w_{1} c_{i}+w_{2} f_{i}
\end{aligned}
$$

Form energy function (11), the dynamics of the model for updating neuron inputs are defined as follows: 


$$
\begin{gathered}
\frac{\partial E}{\partial V_{i}}=\left\{\left(b_{i}+2 c_{i} V_{i}\right)+\left[V_{\lambda}+\beta\left(P_{D}+P_{L}-\sum_{i=1}^{N} V_{i}\right)\right]\left(\frac{\partial P_{L}}{\partial V_{i}}-1\right)+U_{i}\right\} \\
\frac{\partial E}{\partial V_{\lambda}}=\Delta P=\sum_{i=1}^{N} P_{i}-P_{L}-P_{D} \\
\frac{\partial P_{L}}{\partial V_{i}}=2 \sum_{j=1}^{N} B_{i j} V_{j}+B_{i 0}
\end{gathered}
$$

The inputs of neurons at iteration $\mathrm{n}$ are updated as follows:

$$
\begin{gathered}
U_{i}^{(n)}=U_{i}^{(n-1)}-\alpha_{i} \frac{\partial E}{\partial V_{i}} \\
U_{\lambda}^{(n)}=U_{\lambda}^{(n-1)}+\alpha_{\lambda} \frac{\partial E}{\partial V_{\lambda}}
\end{gathered}
$$

The outputs of continuous neurons are determined as follows:

$$
V_{i}=g\left(U_{i}\right)=\left(\frac{P_{i \max }-P_{i \min }}{2}\right)\left[1+\tanh \left(\sigma U_{i}\right)\right]+P_{i \min }
$$

Where $\sigma$ is slope of sigmoid function that determines the shape of the sigmoid function and is set to 100 for all test systems.

The output of the multiplier neuron is determined by a transfer function as follows:

$$
V_{\lambda}=g\left(U_{\lambda}\right)=U_{\lambda}
$$

Stopping Criteria: The algorithm of ALHN will be terminated when either maximum error $E r r_{\max }$ is lower than a predefined threshold $\varepsilon$ or maximum number of iterations $N_{\max }$ is reached.

\section{Best Compromise Solution by Fuzzy-Based Mechanism}

One of the methods to find the best compromise solution from Pareto-optimal front is fuzzy satisfying method [12]. The fuzzy goal is represented in linear membership function as follows [12]:

$$
\mu\left(F_{j}\right)=\left\{\begin{array}{lll}
1 & \text { if } & F_{j} \leq F_{j \mathrm{~min}} \\
\frac{F_{j \mathrm{max}}-F_{j}}{F_{j \mathrm{max}}-F_{j \mathrm{~min}}} & \text { if } & F_{j \mathrm{~min}}<F_{j}<F_{j \mathrm{max}} \\
0 & \text { if } & F_{j} \geq F_{j \mathrm{max}}
\end{array}\right.
$$

Where $F_{j}$ is the value of objective $j ; F_{\text {jmax }}$ and $F_{\text {jmin }}$ are maximum and minimum values of objective $j$, respectively.

For each $k$ non-dominated solution, the membership function is normalized as follows [13]:

$$
\mu_{D}^{k}=\sum_{i=1}^{N o b j} \mu\left(F_{i}{ }^{k}\right) / \sum_{k=1}^{N p} \sum_{i=1}^{N o b j} \mu\left(F_{i}{ }^{k}\right)
$$

where $\mu_{D}^{k}$ is the cardinal priority of $k$ th non-dominated solution, $\mu\left(F^{k}{ }_{i}\right)$ is membership function of objective $j, N_{o b j}$ is number of objective functions, and $N_{p}$ is number of Pareto-optimal solutions.

The solution that attains the maximum membership $\mu_{D}^{k}$ in the fuzzy set is chosen as the 'best' solution based on cardinal priority ranking:

$$
\operatorname{Max}\left\{\mu_{D}^{k}: k=1,2, \ldots, N_{p}\right\}
$$




\section{Results and Discussions}

The algorithm of AHLN is run on an Intel $1.8 \mathrm{GHz}$ PC with $4 \mathrm{~GB}$ of Ram. The ALHN is tested on two systems. The first and second systems have three and six thermal units, respectively. For termination criteria, the maximum tolerance $\varepsilon$ is set to $10^{-4}$ for all dispatches.

\subsection{Test System I}

In the section, a system with three thermal units and transmission losses is considered. The data for the system is taken from [5].

The economic dispatch and environmental dispatch are respectively carried out by setting $w_{1}$ and $w_{2}$ in equation (8) to 1 and 0 , and 0 and 1 . The result for economic dispatch and emission dispatch obtained by ALHN are respectively reported in Tables 1 and 2 along with that from other methods. The cost, emission and computational time comparison have revealed that the ALHN can get either approximate or higher solution and faster convergence speed than Tabu Search [3], NSGA-II [5] and CSA [11].

For determining the best compromise solution, i.e. solution of economic emission dispatch, $w_{1}$ and $w_{2}$ in equation (8) are set to from 0 to 1 with unequal step depending on the obtained solution. The set of solutions for the cases is depicted in Figure 1. Fuzzy-Based Mechanism is then used to determine the best compromise and result is given in Table 3. Clearly, ALHN can get better cost and faster execution time than NSGA-II [5] and CSA [11] while the three methods obtain the same emission.

Table 1. Result Comparison for the Economic Load Dispatch for System 1

\begin{tabular}{|l|l|l|l|l|l|}
\hline \multicolumn{1}{|c|}{ Unit } & $\begin{array}{c}\text { Tabu Search } \\
{[3]}\end{array}$ & $\begin{array}{c}\text { NSGA-II } \\
{[5]}\end{array}$ & $\begin{array}{c}\text { BBO } \\
{[7]}\end{array}$ & \multicolumn{1}{c|}{ CSA[11] } & \multicolumn{1}{c|}{ ALHN } \\
\hline P1 (MW) & 435.69 & 435.885 & 435.195 & 435.1984 & 435.2582 \\
\hline P2 (MW) & 298.828 & 299.989 & 299.972 & 299.9700 & 299.9009 \\
\hline P3 (MW) & 131.28 & 129.951 & 130.662 & 130.6606 & 130.6679 \\
\hline Cost (\$/h) & 8344.60 & 8344.60 & 8344.59 & 8344.59 & 8344.5927 \\
\hline $\begin{array}{l}\text { Emission } \\
\text { (kg/h) }\end{array}$ & 0.09863 & 0.0986 & 0.09869 & 0.09869 & 0.09869 \\
\hline Cpu (s) & - & - & - & 0.09 & 0.01 \\
\hline
\end{tabular}

Table 2. Result Comparison for the Emission Dispatch for System 1

\begin{tabular}{|c|l|l|l|l|l|}
\hline Unit & $\begin{array}{c}\text { Tabu Search } \\
{[3]}\end{array}$ & $\begin{array}{c}\text { NSGA-II } \\
{[5]}\end{array}$ & $\begin{array}{c}\text { BBO } \\
{[7]}\end{array}$ & \multicolumn{1}{c|}{ CSA[11] } & ALHN \\
\hline P1 (MW) & 502.914 & 505.81 & 508.576 & 508.5804 & 508.4998 \\
\hline P2 (MW) & 254.294 & 252.951 & 250.446 & 250.4425 & 250.5012 \\
\hline P3 (MW) & 108.592 & 106.023 & 105.724 & 105.7229 & 105.7456 \\
\hline Cost (\$/h) & 8371.14 & 8363.63 & 8365.11 & 8365.11 & 8365.06 \\
\hline $\begin{array}{c}\text { Emission } \\
(\mathrm{kg} / \mathrm{h})\end{array}$ & 0.0958 & 0.09593 & 0.09592 & 0.09592 & 0.09592 \\
\hline Cpu (s) & - & - & - & 0.07 & 0.015 \\
\hline
\end{tabular}




\section{Table 3. Result Comparison for the Economic Emission Dispatch for} System 1

\begin{tabular}{|c|l|l|l|}
\hline Unit & \multicolumn{1}{|c|}{ NSGA-II [5] } & CSA [11] & ALHN \\
\hline P1 (MW) & 470.957 & 470.9502 & 470.8516 \\
\hline P2 (MW) & 280.663 & 280.7243 & 280.7948 \\
\hline P3 (MW) & 113.675 & 113.6211 & 113.6507 \\
\hline Cost (\$/h) & 8349.72 & 8349.722 & 8349.6957 \\
\hline $\begin{array}{c}\text { Emission } \\
\text { (kg/h) }\end{array}$ & 0.09654 & 0.09654 & 0.09654 \\
\hline Cpu (s) & - & 0.09 & 0.014 \\
\hline
\end{tabular}

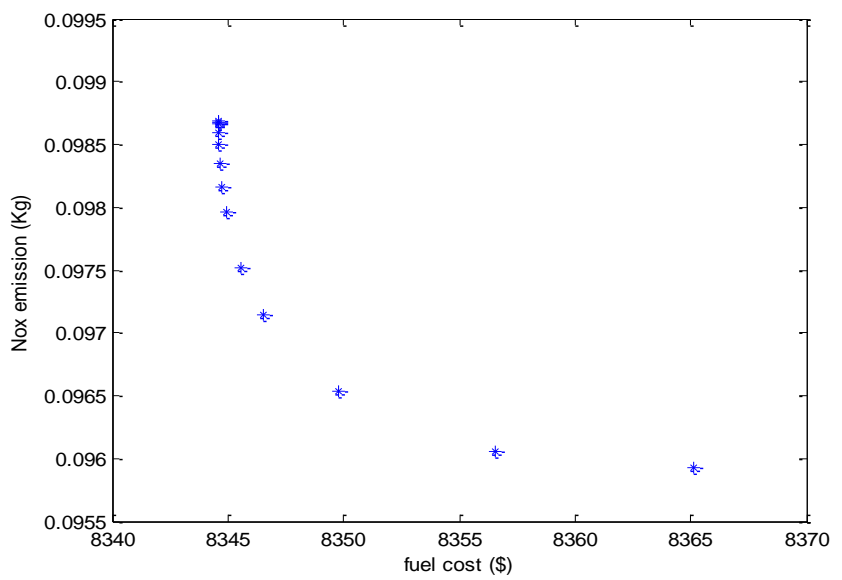

Figure 1. Pareto-optimal Front for Fuel Cost and Emission for System I

\subsection{Test System II}

In the section, a system with six thermal units and without transmission losses is considered. The load demand is $1800 \mathrm{MW}$. The data of the system including fuel cost function and emission function are taken from [4]. Similar to system 1, three cases of dispatch are performed and the obtained results are indicated in Tables 4, 5 and 6. As observed from table 4, ALHN and CSA have the same cost and whereas FCGAs [4] and CGAs [4] obtain the highest cost. ALHN is the fastest one among the four reported methods. For emission dispatch and economic emission dispatch, ALHN and CSA get the same cost and emission; however, the ALHN is still faster than CSA.

\section{Table 4. Result Comparison for the Economic Dispatch for System 2}

\begin{tabular}{|l|r|r|r|r|}
\hline \multicolumn{1}{|c|}{ Method } & \multicolumn{1}{c|}{ CGAs [4] } & \multicolumn{1}{c|}{ FCGAs [4] } & \multicolumn{1}{c|}{ CSA [11] } & \multicolumn{1}{l|}{ ALHN } \\
\hline $\mathrm{P}_{1}(\mathrm{MW})$ & 222.42 & 250.49 & 248.0009 & 248.01 \\
\hline $\mathrm{P}_{2}(\mathrm{MW})$ & 190.73 & 215.43 & 217.7156 & 217.72 \\
\hline $\mathrm{P}_{3}(\mathrm{MW})$ & 95.36 & 109.92 & 75.1775 & 75.191 \\
\hline $\mathrm{P}_{4}(\mathrm{MW})$ & 555.63 & 572.84 & 588.0389 & 588.03 \\
\hline $\mathrm{P}_{5}(\mathrm{MW})$ & 367.92 & 325.66 & 335.5298 & 335.52 \\
\hline $\mathrm{P}_{6}(\mathrm{MW})$ & 367.92 & 325.66 & 335.5372 & 335.537 \\
\hline Cost $(\$ / h)$ & 16589.05 & 16585.85 & 16579.33 & 16579.33 \\
\hline Cpu (s) & 19.66 & 10.44 & 0.062 & 0.01 \\
\hline
\end{tabular}


Table 5. Result Comparison for the Economic Dispatch for System 2

\begin{tabular}{|l|l|r|}
\hline \multicolumn{1}{|c|}{ Method } & \multicolumn{1}{c|}{ CSA [11] } & \multicolumn{1}{l|}{ ALHN } \\
\hline $\mathrm{P}_{1}(\mathrm{MW})$ & 283.4604 & 305.5824 \\
\hline $\mathrm{P}_{2}(\mathrm{MW})$ & 259.3104 & 305.5923 \\
\hline $\mathrm{P}_{3}(\mathrm{MW})$ & 126.2102 & 200 \\
\hline $\mathrm{P}_{4}(\mathrm{MW})$ & 412.8611 & 251.4163 \\
\hline $\mathrm{P}_{5}(\mathrm{MW})$ & 359.0789 & 368.7037 \\
\hline $\mathrm{P}_{6}(\mathrm{MW})$ & 359.0789 & 368.7052 \\
\hline Emission(Kg/h) & 2511.9957 & 2511.9957 \\
\hline Cpu (s) & 0.03 & 0.008 \\
\hline
\end{tabular}

Table 6. Result Comparison for the Economic Emission Dispatch for System 2

\begin{tabular}{|l|l|r|}
\hline \multicolumn{1}{|c|}{ Method } & \multicolumn{1}{c|}{ CSA [11] } & \multicolumn{1}{l|}{ ALHN } \\
\hline $\mathrm{P}_{1}(\mathrm{MW})$ & 283.4604 & 283.4531 \\
\hline $\mathrm{P}_{2}(\mathrm{MW})$ & 259.3104 & 259.3118 \\
\hline $\mathrm{P}_{3}(\mathrm{MW})$ & 126.2102 & 126.2125 \\
\hline $\mathrm{P}_{4}(\mathrm{MW})$ & 412.8611 & 412.8607 \\
\hline $\mathrm{P}_{5}(\mathrm{MW})$ & 359.0789 & 359.0891 \\
\hline $\mathrm{P}_{6}(\mathrm{MW})$ & 359.0789 & 359.0727 \\
\hline Cost $(\$ / \mathrm{h})$ & 16641.901 & 16641.904 \\
\hline Emission(Kg/h) & 2790.9434 & 2790.9343 \\
\hline Cpu (s) & 0.034 & 0.009 \\
\hline
\end{tabular}

\section{Conclusion}

In this paper, a Augmented Lagrange Hopfield Network has been proposed for solving economic emission load dispatch. The ALHN is the combination of augmented Lagrange function and Hopfield neural network in aim to improve performance in terms of convergence speed and getting global optimization. In fact, the proposed ALHN has been tested on two systems with several dispatch including economic dispatch, emission dispatch and economic emission dispatch. The result comparisons are carried out among the ALHN and several methods have shown that ALHN can get either approximate or better solution and faster execution time than all methods reported in the paper. The statement can give the conclusion that the proposed ALHN is very effectiveness and robustness for solving EELD problem.

\section{References}

[1] N. T. Thang, "Economic emission load dispatch with multiple fuel options using Hopfiled Lagrange Network", International Journal of Advanced Science and Technology, vol. 57, (2013), pp. 9-24.

[2] T. D. Kin, M. E. El-Hawary and F. El-Hawary, "Optimal Environmental Dispatching of Electric Power Systems via an Improved Hopfield Neural Network Model”, IEEE Trans. on Power Sysfems, vol. 10, (1995), pp 1559-1565.

[3] C. A. Roa-Sepulveda, E. R. Salazar-Nova, E. Gracia-Caroca, U. G. Knight and A. Coonick, "Environmental Economic Dispatch via Hopfield Neural Network and Taboo Search", UPEC 96 Universities Power Engineering Conference, Crete, Greece, (1996), pp 1001-1004.

[4] Y. H. Song, G. S. Wang, P. Y. Wang and A. T. Johns, "Environmental/econoimic dispatch using fuzzy logic controlled genetic algorithm", IEE Proc-Gener. Transm. Distrib, vol. 44, (1997), pp 377-382. 
[5] C. S. Harry, Rughooputh, T. F. Robert and A. King, "Environmental/Economic Dispatch of Thermal Units using an Elitist Multiobjective Evolutionary Algorithm", Industrial Technology, 2003 IEEE International Conference in Maribor, Slovenia 1, (2003), pp. 48-53.

[6] K. Kamal and N. Chakraborty, "Effect of Control Parameters on Differential Evolution based Combined Economic Emission Dispatch with Valve-Point Loading and Transmission Loss", International Journal of Emerging Electric Power Systems, vol. 9, (2008), pp. 1-18.

[7] P. K. Roy, S. P. Ghoshal and S. S. Thakur, "Combined economic and emission dispatch problems using biogeography-based optimization”, Electr Eng., vol. 92, (2010), pp. 173-184.

[8] M. Basu, "Economic environmental dispatch using multi-objective differential evolution", Applied Soft Computing, vol. 11, (2011), pp. 2845-2853.

[9] A. M. Elaiwa, X. Xiab and A. M. Shehata, "Hybrid DE-SQP and hybrid PSO-SQP methods for solving dynamic economic emission dispatch problem with valve-point effects", Electric Power Systems Research, vol. 103, (2013), pp. 192-200.

[10] H. Hamedi, "Solving the combined economic load and emission dispatch problems using new heuristic algorithm", Electrical Power and Energy Systems, vol. 46, (2013), pp. 10-16.

[11] N. T. P. Thao and N. T. Thang, "Environmental Economic Load Dispatch with Quadratic Fuel Cost Function Using Cuckoo Search Algorithm", International Journal of u- and e- Service, Science and Technology, vol. 7, no. 2, (2014), pp. 199-210.

[12] M. Sakawa, H. Yano and T. Yumine, "An interactive fuzzy satisfying method for multi-objective linear programming problems and its applications", IEEE Trans. Systems, Man, and Cybernetics, vol. 17, no. 4, (1987), pp 654-661.

[13] A. George, M. C. Reddy and A. Y. Sivaramakrishnan, "Multi-objective, short-term hydro thermal scheduling based on two novel search techniques", International Journal of Engineering Science and Technology, vol. 2, no. 11, (2010), pp. 7021-7034.

\section{Authors}

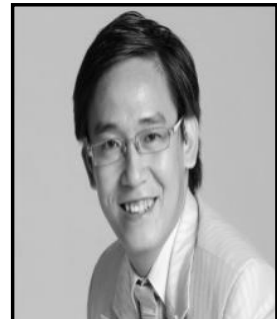

Cuong Dinh Tran, he has graduated from the University of Technology Ho Chi Minh city, Ho Chi Minh city, VietNam. He received her B.Eng and M.Eng degrees in Electrical Engineering in 2005 and 2008, respectively. Now, he is teaching at department of electrical engineering, Ton Duc Thang University, Ho Chi Minh city, Vietnam. His research interests include intelligent control system, power system operation and control and Renewable Energy.

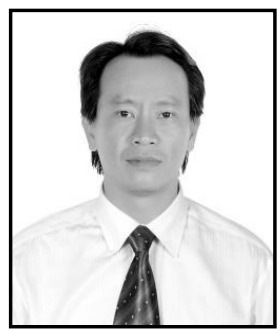

Sang Dang Ho, he received his B.Eng. and M.Eng degrees in Electrical Engineering from Ho Chi Minh University of Technology, Ho Chi Minh city, Vietnam in 2005 and 2008, respectively. Now, he is teaching at department of electrical and electronics engineering, Ton Duc Thang University, Ho Chi Minh city, Vietnam. His research interests include optimization of power system and electric machines control. 